\title{
Research on the Present Situation and Rationality of the Taxi Price Structure
}

\author{
Ruifen SUN \\ Huaqing College of Xi'an University of Architecture and Technology, Xi'an, Shanxi, Chin
}

\begin{abstract}
In recent years, there have appeared the taxi outage events all over the country, causing widespread concern in society. The paper makes a research on the taxi price. Firstly, analyzing price structure on the representative city of our country, and combining the operation cost and profit rate and other indicators to explore the rationality of the taxi price. Secondly, from the economics perspective, the irrationality of our taxi price is concluded, and then the paper gives several price rationalization proposals.
\end{abstract}

KEYWORD: Taxi; Price; Economics; Rationality

The taxi industry plays a decisive role in the development of city traffic as the city public traffic regulation and supply power. In recent years, the taxi industry has grown in strength, which occupies a city road which is a scarce resource, and caused some pollution on the environment, so the government has to implement the control of taxi industry. The main contents of control are quantity control, price control, etc. To implement the control makes a contrary to the rationality of economics which competing in the market achieve efficient on the allocation of resources. So the price of taxi industry appears some unreasonable phenomenon. This paper analyzes the composition and optimization research of Chinese taxi industry price.

\section{THE TAXI PRICE STRUCTURE OF THE CURRENT SITUATION IN CHINA}

\subsection{The taxi charges of Beijing in 2014}

Fees:

1) The starting price: 3 kilometers fees for 13 yuan;

2) Price: beyond three $\mathrm{km}$, basic price for 2.3 yuan / km;

3) The low speed travel fee and the waiting fee: according to the requirements of passengers waiting or due to road conditions, speed is less than 12 kilometers, every 5 min during the peak of morning and evening, extra 2 kilometers fee (not including Kongshi fees), other times extra 1 kilometers fee(not including Kongshi fees).
4) Booking taxi service fee: booking more than 4 hours in advance for each 6 yuan, less than 4 hours reservation for 5 yuan each;

5) Kongshi fees: one-way passenger more than 15 $\mathrm{km}$ section, the basic price $50 \%$ extra charge; roundtrip passenger (starting and ending within the scope of $2 \mathrm{~km}$ (including) not adding Kongshi fees.

6 )Night charge: 23:: 00 (inclusive) to the 5:00 (do not contain) operation, the basic price is $20 \%$ extra charge.

7) Carpool toll: by mileage part, according to the non carpool case payment payable in full $60 \%$.

8) Fuel additional fee: 1 yuan / shipments.

Note:

1) Early peak is 7:00 (including) $-9: 00$ (do not contain); evening peak is 17:00(including) $-19: 00$ (not included).

2) Taxi segment mileage is accurate to 500 meters, the time is precise to 2.5 minutes

3) Crossing, bridge tolls are burden by passengers .

At the same time, Beijing provides a taxi fuel surcharge dynamic adjustment measures. In January 15,2015 , Beijing cancelled the taxi fuel surcharge 1 yuan / shipments.

\subsection{The taxi charges of shanghai in 2014}

During 5:00---23:00, the initial cost is 14 yuan (including fuel costs for 1 yuan), and can run 3 kilometers. More than 3 kilometers the price is 2.40 yuan per kilometer. The price is 3.60 yuan per kilometer if the total mileage is more than 10 kilometers. 
In the 23:00--- to the 5:00 period, the initial cost is 18 yuan (including fuel costs for 1 yuan ), and can run 3 kilometers. More than 3 kilometers the price is 3.10 yuan per kilometer. The price is 4.70 yuan per kilometer if the total mileage is more than 10 kilometers. Waiting fees: waiting fee is 0.52 yuan for 1 minutes.

From the taxi fee standards in these typical cities, we can see that the large and medium-sized cities in China are imposed by the mileage billing fixed rate system, mainly including the starting price, and the initial kilometers, extra kilometer price, waiting fee, fees for back in vain, nightly surcharges etc.

\section{CITY TAXI OPERATION COST AND PROFIT ANALYSIS}

Whether the taxi price is unreasonable or there exists high profits in tax industry, we should compare the price and operating costs.

\subsection{The costs}

As most areas of our country have taken the taxi operating company mechanism, this article analyzes the cost structure from the perspective of the taxi cost of company.

The cost of a taxi including: basic salary, bonus, welfare, vehicle depreciation, management costs of the taxi, business taxes; fuel costs, maintenance fee in the actual operation, maintenance fee for road, insurance fee. (The following is the taxi industry average data of Beijing in 2013)

The taxi company's month cost is 5279.85 yuan / car, including the main business costs and expenses for the period.

First of all, the taxi company's main costs include the cost of labor; vehicle related costs; rental fees; a total of 3984.80 yuan / car / month.

1) "Labor cost" for 1901.85 yuan / car / month. This part of the cost is paid by enterprises to drivers, including payments to the drivers "the direct labor", and each car is 796 yuan per month on average; the worker welfare funds according to the total amount of wages in accordance with the provisions of the proportion; union funds; staff education; "five risk a gold" and "supplementary insurance" in accordance with the provisions of laws and regulations by the enterprise to the workers; in addition to some drivers labor supplies, tooling costs; heating fees for the old staff reimbursement , etc.

2)"Vehicle related costs" is 2078.08 yuan / car / month. There are three parts share the most part of the costs. The first is the vehicle depreciation; the second is the fuel subsidies releasing to the pilot in accordance with the provisions of the competent department of industry enterprise, an average of
629.44 yuan / car / month; the third expenses related to vehicle insurance, annual inspection, examination, meter test, GPS communication fees and travel tax. There are two smaller costs in vehicle related costs, respectively the vehicle fuel and vehicle maintenance fee. The fee directly related to the production activities and operation, such as occurred in the vehicle replacement, maintenance and so on.

3) "Rental fee" mainly refers to the enterprise charges of renting parking place .

The fees during the period include "management fees" and "finance charge", a total of 1295.05 yuan / car / month.

1) "Management fees" is a total of 1249.63 yuan / car / month. The "wages and price of labor" mainly refers to the salary; bonus; welfare; five insurance; union funds; education funds."Depreciation" mainly refers to the depreciation of fixed assets of enterprises in addition to the vehicle; "office expenditure" mainly includes the communication fees; office vehicle fees; the daily repair and maintenance and daily management activities of the material consumption costs; "restructuring costs amortized" mainly refers to the policy of asset reorganization occurred in 2002 before the end of the relevant expenses; this part of the cost must be relevant with rental business. "Others" include fire security costs; depreciation; amortization of intangible assets and deferred assets; property costs; green fees; promotional fees etc.

2) "The financial cost is average 45.42 yuan per vehicle per month, mainly financial costs for shortterm loans of updating vehicle.

According to the city development and Reform Commission, in the costs of the enterprise to pay for the taxi, the driver job subsidies, five social insurance and one housing fund, employee welfare costs accounted for about 1/3, and vehicle depreciation, driver fuel subsidies costs accounted for about 1/3, in addition, there are vehicle inspection, vehicle insurance, employee supplementary insurance, vehicle repairment and maintenance, enterprise management cost.

\subsection{Taxi profit rate}

There are 66000 taxis in Beijing by the end of 2013, which consists of two bus and single bus. The single bus monthly money is 5175 yuan, 8280 yuan for the double bus. In accordance with the single, double bus ratio of $6: 4$, the city's taxi money monthly turned over 4 million yuan. Hearing from released announcement, the operating income of a Beijing taxi is 16300 yuan monthly. From the expenditure, in the 16300 yuan, enterprise costs account for 33\%, and the driver's net operating income is $22 \%$, profits accounting for the $3 \%$. 
The profit of enterprises per vehicle month: 16300 yuan $x 3 \%=489$ yuan (about 500 yuan)

Corporate profit rates: $98 \%$ of taxi company's income comes from monthly money,to see it as the total income in the calculation. There are 66000 taxis in Beijing. Single, double class ratio is 6: 4.

Single bus number: 66000 x $0.6=39600$; double bus number: 66000 x $0.4=26400$;

The company's total revenue: single bus money 5175 yuan x 39600 vehicles + double bus money 8280 yuan $x 26400$ vehicles $=42352$ million;

Average revenue per car: 423520000 yuan $\div 66000$ cars $=6417$ yuan;

The rate of profit: the total profit 500 yuan $\div 6417$ yuan of income $=0.078$ (about $8 \%$ ).

From the profit rate, we can see that the taxi industry is broadly in line with the social rate of return on investment and there don't exist too much excess profits.

\section{PROBLEMS OF THE TAXI PRICE.}

\subsection{Operational data announced by taxi companies remains to be verified}

As the taxi companies hold all the information about taxi, so the traffic control department only depends on taxi enterprises providing information of taxi to make a calculation of the operation cost data, thus the corresponding price to be made. However, because of their own interests, whether the taxi companies' operating costs is true indeed to be verified.

\subsection{The price doesn't play the role of industry barometer.}

In economics, the intersect of supply and demand curves decides the price. As shown in Figure.

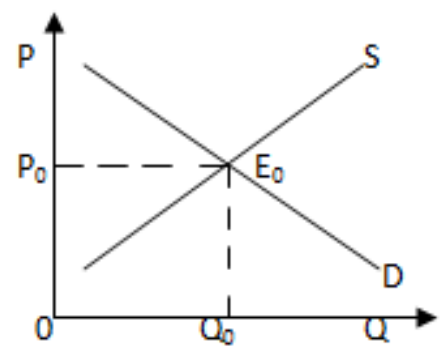

Figure 1: supply and demand curves

The price mechanism plays a regulatory role in many aspects in the operation and development of social economy.

1) Adjusting production and investment direction and scale, that is, adjusting the allocation of resources;
2) Regulation of commodity supply and demand relations, regulating the structure and direction of consumption demands ;

3) To adjust the income distribution;

4) Adjusting the progress of technology and management.

The price mechanism is the core of the market economy, and it is a necessary condition to achieve the basic status of the market in the allocation of resources. But the price mechanism has its certain application conditions. Due to the special properties of the taxi industry of quasi public products, the taxi price after controlled lost a series of function which the price as a barometer guides the industry supply and demand.

In economics, when supply exceeds demand, the market price is less than market value; as for less than demand, the market price is greater than the market value. But in the present stage, taxies are often in short supply, regulated prices do not correspond with the taxi value. From this perspective, the taxi market doesn't achieve the optimal allocation of resources, and has some resource wasting.

\section{PROPOSALS TO OPTIMIZE THE TAXI PRICE.}

\subsection{On the basis of economic theory of reasonable price, not blindly raising prices}

A lot of people think that the people who take a taxi belong to the community of high income before, but through the market survey, the argument is untenable. In general travel, the people who take a taxi do not belong to the high-income strata of society, with the popularization of cars, high income people have private cars, consumers of taxies mostly belong to working-class, they take a taxi for some urgent business, otherwise for sick or with many things, not convenient to travel. So for this crowd, the price elasticity of the taxi is big.

From the angle adding income of the taxi driver, raising price is not a wise choice. But that is not to say that only taking the reduction strategies can increase revenue. To form a reasonable price ratio system in taxies, subway, and buses which is to make the price of a taxi to divert a portion of travel demand to public transport, but also makes the taxi price to be accepted by the working class.

\subsection{Establishing the perfect laws and regulations. Standardizing the information disclosure of the taxi enterprises.}

Relevant government departments should strengthen the management of the taxi enterprises, and entrust the accounting firms and other institutions for financial guidance and audit supervision on the taxi 
enterprises. Solving and correcting the taxi enterprises' management problems timely, and gradually realizing the taxi operating costs to the public.

\subsection{Gradually introducing new energy automobile substituting taxies for fuel.}

The taxi industry is in big scale, and the "parade" operating characteristics make a huge consumption in energy. If it can be gradually introduced new energy vehicles for replacement to fuel vehicle, not only can reduce the environmental pollution, and new energy vehicles with lower operating costs will make the taxi fares more approachable, so as to improve the rate of actual loading.

\section{CONCLUSION}

Because of the special attributes, the taxi price is related to many factors. Although the taxi industry has been criticized, the traffic management department of each area in our country constantly holds hearings for taxi fares, soliciting opinions and proposals from many parties. As can be seen, the further development of the rationalization of the taxi price is the inevitable trend.

\section{REFERENCES}

[1] Chen Xiumei, Han Keyong. The economic analysis of taxi price adjustment in Beijing. Journal of Shanxi Normal University (SOCIAL SCIENCE EDITION), 2013,11,40 (6): 58-60.

[2] Zheng Guitong. The theory research based on taxi price. Enterprise reform and management, 2014, (11): 206

[3] Wang Xiufang. To investigate the scheme of city taxi price adjustment. China collective economy, 2011.36 (12):192.

[4] Lu Qing, Chen Qi. Discussion on City taxi price management problems. Traffic enterprise management, 2012, (8): 22-23.

[5] Yang Zhongzhen, Wang Lu. A model of city taxi starting price analysis. Journal of Dalian Maritime University, 2006, 2,32 (1): 38-41.

[6] Zhang Xia, Jiang Xiaochuan, Huang Chengfeng. The study of city taxi fares structure optimization. Traffic enterprise management, 2010,(7): 8-10.

[7] Cheng Shidong. Positioning and reforming of the taxi management. Integrated transportation, 2012, (6): 33-35.

[8] Li Yujuan, the taxi industry problems and price correction.Chongqing social science, 2010, (1): 36-40.

[9] Yu Yingjing. The survey and analysis of regulation on taxi price.China business , 2010, (11): 188

[10] Yang Fan, Yang Qi, Zhang Jun,Xi Enchong. Public transport pricing and optimal government compensation model. Journal of traffic and transportation engineering, 2010,4,10 (2): 110-115 